\title{
The rhetoric appeal to identity on websites of companies offering non-health-related DNA testing
}

\author{
Anders Nordgren
}

Received: 1 March 2010 /Accepted: 13 August 2010/Published online: 24 August 2010

C) The Author(s) 2010. This article is published with open access at Springerlink.com

\begin{abstract}
During the last few years a large number of companies have emerged offering DNA testing via the Internet "direct-to-consumer". In this paper, I analyse the rhetoric appeal to personal identity put forward on the websites of some of these consumer genomics companies. The investigation is limited to non-health-related DNA testing and focuses on individualistic and communitarian-in a descriptive sense-visions of identity. The individualistic visions stress that each individual is unique and suggest that this uniqueness can be supported by, for example, DNA fingerprinting. The communitarian visions emphasise that individuals are members of communities, in this case genetic communities. It is suggested that these visions can be supported by, for example, various types of tests for genetic ancestry tracing. The main part of the paper is devoted to an analysis of these communitarian visions of identity and the DNA tests they refer to.
\end{abstract}

Keywords Direct-to-consumer genetic testing - Genetic testing - DNA testing · Genetic ancestry testing · Identity

During the last 10 years numerous companies have emerged that offer DNA testing online. Their services are "direct-to-consumer". They provide healthrelated DNA information, non-health-related DNA information, or both. The recent and sudden emergence of these consumer genomics companies has raised a lot of debate, not least from an ethical and policy perspective (see e.g. Human Genetics Commission 2003, 2007; Hudson et al. 2007; Kaye 2008; Hogarth et al. 2008; Borry 2009). In this paper, I will analyse the rhetoric appeal to personal

\footnotetext{
A. Nordgren $(\bowtie)$

Linköping University, Linköping, Sweden

e-mail: anders.nordgren@liu.se
} 
identity that can be found on the websites of some of these companies. My analysis is limited to appeals to identity that refer to non-health-related DNA testing such as DNA fingerprinting and genetic ancestry tracing. Together with my colleague Eric T. Juengst, I have elsewhere analysed the appeal to identity on such websites more generally with a focus on both health-related and non-health-related DNA testing (Nordgren and Juengst 2009). In the present paper, however, I focus on non-health-related DNA testing exclusively and investigate individualistic and communitarian visions of identity appearing on websites of some companies offering such testing. The main part of the paper is devoted to communitarian visions of identity referring to genetic ancestry tracing. A reason for this is that while the individualistic visions of identity are quite simple and straightforwardeach individual is unique - and refer mainly to DNA fingerprinting, the communitarian visions of identity differ substantially from each other depending on which DNA test - among several different tests - they refer to. A further reason is that some of these visions and DNA tests focus on family and ethnicity, and these notions have been at the centre of the modern discussion of identity (see e.g. Taylor 1989; Kymlicka and Norman 2000; Gutmann 2003). A hypothesis put forward at the end of the paper is that the rhetoric appeal to identity on the websites of some consumer genomics companies can be seen as a response to the search for identity in modern pluralistic societies in which people have become uncertain about who they are.

Let me clarify that I will not discuss whether the rhetoric of identity holds water, i.e., whether the visions are justified or whether the DNA tests are scientifically adequate. Neither will I investigate how common this rhetoric is. The study is purely qualitative. I will only try to establish that a variety of rhetoric appeals to identity appear in this study material.

In order to find an appropriate study sample, I searched the Internet and easily found more than 30 companies - most of them based in the US-offering DNA testing. Although there certainly are many more companies of this type, I found this sample sufficient for my purposes. It should be noted that in my analysis I do not directly refer to each of these companies but only to some of them. The overwhelming majority of the companies offer non-health-related DNA testing only: African Ancestry (2010), Ancestor.com (2010), Ancestor-DNA (2010), Ancestry.com (2010), Determigene (2010), DNA Ancestry Project (2010), DNA Consultants (2010), DNA Diagnostics Center (2010), DNA Heritage (2010), DNAPrint Genomics (2010), DNA Tribes (2010), DNA Worldwide (2010), EthnoAncestry (2010), Family Helix (2010), Family Tree DNA (2010), Genetree (2010), GTLDNA (2010), Homednadirect (2010), Identigene (2010), International Biosciences (2010), Mygene (2010), Mygenetree (2010), Oxford Ancestors (2010), Roots For Real (2010), The Genographic project (2010), and Warrior Roots (2010). A few companies offer both non-health-related and healthrelated DNA testing: deCODEme, DNA Direct (2010), Genelex (2010), Nimble Diagnostics (2010), and 23andMe (2010). Finally, three companies in the sample provide health-related DNA testing only, however these will not be analysed here other than by way of exception: Gene Essence (2010), Knome (2010), and Navigenics (2010) (for web addresses, see References). 


\section{Web-rhetorics}

Consumer genomics companies may use different methods to attract consumers. The method to be analysed in this paper is to appeal to personal identity. Here is an example that can be found on the website of DNA Worldwide:

For thousands of years mankind has always wanted to know; who are we? Where do we come from? And what makes us unique? Now thanks to advances in DNA and genetics we can start to answer some of these questions (DNA Worldwide 2010).

The type of identity alluded to is narrative identity, i.e., identity based on stories about who an individual is created by herself or the community to which she belongs (see e.g. MacIntyre 1981). In the quotation, we see that the company maintains that DNA testing can provide an input to an understanding of who we are. However, as we will see below, there might also be an implicit reference to numerical identity, i.e., identity as continuity-over-time. The individual remains the same during change (see e.g. Parfit 1984; for a more general discussion of genetics and various conceptions of identity, see Nordgren 2008).

Personal identity can be health-related as well as non-health-related, and some companies offer DNA information that can be relevant to both aspects. For example, genetic disease risk testing may provide input to health-related identity, leading to a new self-understanding: "I am a person at risk of developing a heart disease". Similarly, DNA information may be relevant to non-health-related identity: "I am P's father" (based on a paternity test) or "I am an African-American with my roots in Nigeria" (based on genetic ancestry tracing). In this paper, however, I focus exclusively on how the websites of some companies appeal to non-health-related identity by referring to non-health-related DNA information.

On the websites non-health-related DNA information is used to support individualistic and communitarian visions of personal identity. I use the term "vision" for two reasons. First, the statements about identity on the websites are interpretations of test results rather than scientific conclusions. They work as rhetoric tools. They are ways of framing the service of DNA testing in order to sell it to potential customers who search for their personal identity. Second, the notion of identity is never defined or developed in any detail but is only more or less explicitly indicated. The term "vision" underlines its vagueness and imaginative character. For the following analysis, I suggest these stipulative definitions:

An "individualistic" vision of (narrative) identity=def. a vision that an individual's identity is unique in the sense that it is different from all other individuals' identities.

A "communitarian" vision of (narrative) identity=def. a vision that an individual's identity is shared by other individuals belonging to the same community.

Note that I use the terms "individualistic" and "communitarian" in a descriptive sense, not in a normative-i.e., social, political or ethical-sense. 


\section{Individualistic visions of identity referring to non-health-related DNA information}

The individualistic visions stress that each individual is unique. Such visions of identity are illustrated in the following two quotations. International Biosciences points out:

We each have thousands of genes, half supplied by each of our parents. With the exception of identical twins, each person's genetic identity is unique, it is this very uniqueness that makes DNA profiling so accurate (International Biosciences 2010).

DNA Worldwide stresses:

Your DNA determines who and what you are. No one has ever had the same DNA as you; it is the source of your uniqueness (DNA Worldwide 2010).

The individualistic visions of identity explicitly expressed in these quotations are clear examples of genetic individualism. Genetic individualism is the view that the DNA of an individual gives the individual a unique identity.

In addition to explicit expressions, there are also many other more indirect examples of individualistic visions of identity on the websites. Some companies indicate individualistic visions of identity by stressing that genetics has become "personalized". 23andMe, for example, points out that "Genetics just got personal" (23andMe 2010). Similarly, the very names of the "me-companies" deCODEme and 23 andMe indicate individualistic visions of identity. The name of the Icelandic company deCODEme stresses that decoding the genetic code may provide important clues to personal identity (deCODEme 2010). The name "23andMe" indicates that the 23 chromosome pairs are closely linked to "me" as an individual person (23andMe 2010).

The main DNA testing method referred to in order to support genetic individualism is DNA fingerprinting. This method is used in forensics to establish unique individual identity. In this case, identity is not only a matter of a unique narrative identity but also of numerical identity, i.e., identity in terms of individual continuity-over-time. The DNA fingerprint of an individual remains the same over time. DNA Consultants offer a "DNA Fingerprint Test" that uses the standard markers from US forensics, the CODIS profile. These markers are STRs (short tandem repeats), i.e., locations on the chromosomes where a pattern of two or more nucleotides is repeated. In addition, the company uses various population-specific markers (DNA Consultants 2010; see further below). DNA Worldwide offers "a high quality certificate print of your unique DNA image and genetic code to frame or keep safely" and presents this offer under the heading of "Your unique DNA Identity Profile" (DNA Worldwide 2010). DNA Worldwide also offers a DNA storage kit for storing "your genetic makeup forever". This service of storing individual DNA samples for the future-for oneself or one's children-is also an expression of genetic individualism.

Moreover, genetic ancestry tracing may be used to support individualistic visions of identity by stressing each individual's unique ancestry. For example, International 
Biosciences talks about "a person's unique "BioGeographical" identity" (International Biosciences 2010). I will discuss genetic ancestry tracing more in the next section about communitarian visions of identity.

In sum, two types of individualistic visions of identity can be found on the websites based on non-health-related DNA testing.

(1) Unique individual identity The DNA of an individual gives the individual a unique identity in a narrative sense. In support for this view, websites may refer to DNA fingerprinting but also to genetic ancestry tracing.

(2) Identity as continuity-over-time The DNA fingerprint of an individual remains the same over time and thus indicates the numerical identity of the individual.

\section{Communitarian visions of identity referring to non-health-related DNA information}

I will now investigate communitarian visions of identity. For reasons put forward in the introduction, these visions require a much more extensive analysis than the individualistic ones.

The communitarian visions stress that each individual belongs to a community. Genetic communitarianism is the view that the DNA of an individual shows that the individual's identity is shared by other individuals belonging to the same community. The community to which they belong is a genetic community, i.e., a community sharing certain DNA characteristics. As deCODEme points out:

From a genetic point of view we are all unique, but some individuals are more similar than others (deCODEme 2010).

The genetic community may be the genetic family living at present or include ancestors far back, even thousands of years.

Communitarian visions of identity related to the narrow community of the presenttime family — family identity - may refer to, for example, paternity tests, maternity tests and sibling tests, which all use the technique of DNA fingerprinting (see e.g. Genelex 2010; DNA Worldwide 2010). Here is a "customer story" on the website of DNA Worldwide illustrating how sibling tests may provide input to narrative identity:

When I was 15, my Father showed me a photograph of a boy and told me it was given to him by the boy's mother who implied that he was my father's son! The instant I saw it I knew that this boy was my brother. I waited until I was an adult to make my search. Ten years later, I finally found my little brother. But I had to get my family as well as my father to accept him. I came across DNA Worldwide, got my father and new brother to perform the quick, easy procedure, and two weeks later, I could finally prove to the world what I already knew (DNA Worldwide 2010).

We see here how DNA testing may be used to confirm a biological relationship that is experienced to be of vital importance for family identity.

Other communitarian visions of identity are related to genealogical investigations in a broader sense. The company Ancestor.com, which specializes in genealogy and 
which uses many different methods including genetic testing, stresses the link between understanding ancestral roots and understanding personal identity:

In order to better understand ourselves, it is important to understand where we came from (Ancestor.com 2010).

Mygenetree puts it like this, stressing the narrative character of ancestry tracing:

Contained in each of our cells is a unique genetic profile, or fingerprint. This genetic information reveals more than just our individuality; it can tell the story of our ancestral history and provide clues about our ethnic origins (Mygenetree 2010).

Several different tests can be used for genetic ancestry tracing. Some companies provide many different tests, others only a couple. In order to understand different communitarian visions referring to different tests, it is necessary with a fairly detailed description of these tests. My description of the tests, however, is only based on the presentations found on the websites. As pointed out in the introduction, I do not take a stand regarding their scientific adequacy.

The two most common tests are sex-linked: the $\mathrm{Y}$ chromosome test and the mitochondrial-DNA test. DNA information shows that individuals are part of a very long chain that lasts thousands of years back in time. The Y chromosome test concerns only males and traces the paternal line back to "Y Chromosome Adam" who lived in Africa 60,000-80,000 years ago. He was not the only male living at that time but the only who has offspring in an unbroken line still living today. The mitochondrial-DNA test concerns both males and females and investigates the maternal line back to "Mitochondrial Eve" who lived in Africa around 150,000200,000 years ago. In analogy with Y chromosome Adam, she was not the only female living at that time, but she was the only one with an unbroken line of offspring to the present day (Oxford Ancestors 2010). Both the Y chromosome test and the mitochondrial test provide information about only one line of descent (i.e., one ancestor per generation) of all that have contributed to the genetic makeup of the individual. On the basis of these tests, individuals are categorized into haplogroups, i.e., populations defined by certain SNPs (single nucleotide polymorphisms). These are locations where one nucleotide has mutated to a different one. The mutations have occurred at specific points in human history. The tests are based on knowledge about ancient world migrations and evolutionary theory (Oxford Ancestors 2010; The Genographic project 2010; The DNA Ancestry Project 2010). The companies also maintain that it is possible to show relatedness to famous persons in history. Several examples appear on the websites such as Thomas Jefferson and Genghis Khan (The DNA Ancestry Project 2010). Moreover, Y chromosome tests can be combined with an investigation of surnames. In online DNA surname projects individual males upload their DNA results on a company's website and compare them. The tests might determine whether two males with the same surname are related or whether two males with the same surname have a common ancestor (Mygenetree 2010; DNA Heritage 2010).

There are also autosomal marker tests, i.e., tests focusing on non-sex chromosomes that recombine. They measure the likelihood of matches against biogeographic regions around the world. These tests are more recent than the sex- 
linked tests. The autosomal tests are of at least two different types. The first type starts from preconceived racial or ethnic divisions and from knowledge about ancient world migrations and calculates the "genetic percentages" of racial or ethnic admixture. DNAPrint Genomics describes four different biogeographic groups: Native American, European, East Asian, and Sub-Saharan African. These groups correspond roughly to the commonly perceived "races" (see further below). In addition, the company offers a "EURO DNA test", which gives more specific information about European ancestry. The tests measure an individual's mixed geographic heritage by identifying particular SNP markers, called Ancestry Informative Markers (AIMs)(DNAPrint Genomics 2010 (via DNA Diagnostics Center 2010); see also e.g. 23andMe 2010 and DNA Worldwide 2010)

Other autosomal tests use STRs instead of SNPs. They do not start from any presumed biogeographic classifications or preconceived racial or ethnic divisions. Neither are they based on knowledge about ancient world migrations. In contrast to such top-down approaches, they represent bottom-up strategies. As described on some websites, they compute the likelihood of matches against actual objectively identified contemporary populations in various parts of the world. DNA Consultants uses a forensic profile for ancestry tracing - the CODIS profile (see above) - and combines this with a population database called OmniPop and, if appropriate, also with a database of the European Network of Forensic Science Institutes (ENFSI). The matches may be more or less strong (DNA Consultants 2010). DNA Tribes computes the likelihood of matches against 34 world regions, including regions with populations that do not fit the ordinary racial divisions such as those of North Africa, Polynesia or Tibet. The test "measures a person's genetic connections within populations, identifying the ethnic groups and world regions where the person's DNA profile is most common" (DNA Tribes 2010).

The specific method used in the testing determines to which genetic community one is believed to belong, i.e., how the genetic community is considered to be constituted or defined. Different types of communitarian visions of identity are linked to these different views of genetic community. I find it useful to make the following classification (note that these are my analytic categories, not the companies').

(1) mtDNA haplogroup identity By matrilineal testing, the individual female or male is assigned to the genetic community of a particular mtDNA haplogroup. The individual receives his/her identity from being a member of the haplogroup. This type of communitarian identity can therefore be called "mtDNA haplogroup identity". With the mtDNA haplogroup identity follows a story, which underlines its narrative nature (narrative identity), a story about ancient world migrations and evolution. On the website of Oxford Ancestors, the haplogroups are described as clans with ancient clan mothers (around 36 worldwide). The seven European clan mothers are even given names such as Ursula, Xenia and Helena (Oxford Ancestors 2010). The founder of Oxford Ancestors, Bryan Sykes, has also written a book on the subject, The Seven Daughters of Eve, which presents the scientific story about how mtDNA testing emerged (Sykes 2001).

(2) Y haplogroup identity By patrilineal testing, the individual male is assigned to the genetic community of a particular $\mathrm{Y}$ haplogroup. He receives his identity 
from being a member of that haplogroup. It is a community of males lasting through thousands of years back to distant common ancestors.

(3) Biogeographic identity By autosomal marker testing, the individual's degree of match with various genetic regions or populations is determined. These biogeographic regions represent different genetic communities. The results comprise relative matches against different biogeographic regions. The pattern and strength of matches reveal the often mixed "biogeographic identity" of the individual (admixture).

(4) Pedigree identity By participation in an online DNA surname project an individual male can investigate whether there is a genetic link with other, to him previously unknown, males with the same surname. In the case of a link, they belong to the same family tree and this family tree represents a kind of genetic community. The individual receives his identity from this "pedigree identity". Part of the pedigree identity is of course also the connections to other relatives - males and females - as can be discovered by other methods in genealogy including DNA paternity tests, maternity tests, sibling tests and so forth (see above). The genealogical information gained by participation in DNA surname projects may lead to a more complete pedigree, however there may also be a gap between a distant relative found by this method and the rest of the pedigree.

It is vital to note the significance of these distinctions. If the focus is on mtDNA haplogroup identity, you as a female or male customer get one particular story about the migrations of your ancestors and thereby a particular story about who you are. You belong to one particular community with a special narrative identity. According to the companies, it is certain that you belong to that particular haplogroup, but they would probably admit that the details of the story - i.e., the exact migration history - may be scientifically somewhat uncertain. If the focus is on Y haplogroup identity, you as a male customer get another-more or less certain - story about the migrations of your ancestors and thereby another story about who you are. You belong to another community with another narrative identity. In the case of biogeographic identity, you as a customer get information about statistical matches with certain regions or ethnic groups. This means that you as a customer — with higher or lower probability - belong to a particular group or, in cases of admixture, to two or more groups. Belonging to a particular group, you share the group's written and/or oral history and thus the group's narrative identity. Regarding pedigree identity, you as a male customer by investigation of surname and $\mathrm{Y}$ chromosome get connected with other males in a particular pedigree. In this way, you become part of a larger community involving more individuals - previously unknown to you — and their particular life stories. You belong to a community with a particular narrative identity.

The communitarian visions on some websites are further indicated by the fact customers are encouraged to share and compare their DNA information with other people as a social-networking tool (deCODEme 2010). DNA Heritage stresses that "DNA can be the key in connecting individuals, families and entire populations..." (DNA Heritage 2010), and the company African Ancestry explicitly uses the term "Online Community" (African Ancestry 2010). It should be noted that this community is not a genetic community but an Internet community based on common interests in DNA testing. By the Internet interaction, some members of the 
online community might discover that they are members of the same genetic community, in any of the senses above.

\section{Genetics, race and ethnicity}

The communitarian visions of identity on some websites focus on race and ethnicity. Some companies state explicitly that they offer ethnicity tests. This is, for example, how Genelex describes its "Ethnicity DNA Test":

Our Ethnicity DNA Test will provide you with a simple and objective description of your ancestral origins as well as a certificate of your unique genetic fingerprint. The test gives you an estimated percentage of ancestry from four population groups:

1) Native American (those peoples that migrated to inhabit South and North America) 2) Indo-European (Europeans, Middle Easterners and South Asians such as Indians) 3) East Asians (Japanese, Chinese, Koreans, Pacific Islanders)

4) Africans (Sub-Saharan) (Genelex 2010).

Other companies offer similar tests but do not call them ethnicity tests. They avoid this terminology and talk merely about ancestry testing. A third category of companies states explicitly that it does not offer ethnicity testing. The reasons why these companies state that they do not offer ethnicity testing differ, however.

In its FAQs section, Oxford Ancestors responds in the following way to the question "Can a DNA analysis identify my racial or ethnic background?":

No. There is no genetic basis for ethnicity or race. Our MatriLine service identifies your ancient ancestral mother, who lived at a time that pre-dates our notions of ethnicity and race. We know upon which continent all the clan mothers lived, but the modern day descendents of any single clan mother will be from many different countries, ethnic backgrounds and races (Oxford Ancestors 2010).

This response concerns mtDNA testing and stresses that the clan mothers lived at a time that predates our concepts of ethnicity and race and that present-day descendents may come from different ethnic and racial backgrounds. However, other companies use similar tests and still call them ethnicity tests, because later descendents of those individuals that the Oxford Ancestors call the clan mothers come from various ethnic regions of the world.

DNA Tribes has a different angle. It criticizes those ancestry testing companies that start from preconceived racial and/or ethnic divisions (including DNAPrint Genomics referred to above). This is how the company clarifies the issues in its FAQs section:

DNA Tribes is the only genetic ancestry analysis that identifies world regions based on mathematical patterns of unique genetic variation. Other tests rely on non-scientific racial divisions. These presumed racial groupings present an incorrect and incomplete view of genetic patterns actually present in the world. Simplistic divisions of the world into 3-5 continents ignores important unique regions that do not neatly fall into presumed racial categories, such as such as 
North Africa, Polynesia or Tibet. DNA Tribes analysis does not make any assumptions based on non-scientific racial divisions.

Instead of relying on presumed racial divisions, DNA Tribes defines world regions identified in a comprehensive database of world populations by objective mathematical criteria. Many of these world regions correspond to cultural or linguistic groups. For instance, Slavic-speaking peoples share a predominance of the Eastern European region. Other world regions cross national and cultural boundaries as they exist today and reflect the genetic imprint of older patterns of human interactions in these zones (DNA Tribes 2010).

Racial divisions are considered to be non-scientific and not fitting the genetic patterns actually present in the world. There are regions that "do not neatly fall into presumed racial categories". The company nevertheless states that many of the genetic world regions discovered by using its methods correspond to "cultural and linguistic groups", i.e., what we often call ethnic groups.

\section{Some related issues}

I will finish this analysis of websites by briefly addressing a few related issues.

The first issue concerns the relation of genetic individualism and genetic communitarianism. On the websites of the consumer genomics companies, we have seen examples of both. However, both visions can be found on one and the same website. An example is the website of Mygenetree (already quoted above):

Contained in each of our cells is a unique genetic profile, or fingerprint. This genetic information reveals more than just our individuality; it can tell the story of our ancestral history and provide clues about our ethnic origins (Mygenetree 2010).

It remains unclear, however, how these individualistic ("unique") and communitarian ("ancestral", "ethnic") visions of identity relate more precisely. Moreover, there are differences among companies regarding emphasis. Some companies focus more on communitarian visions, others on individualistic.

The second issue concerns whether identity is a biological discovery or a social construction. Some websites stress that identity is to be discovered - at least partly - in the genes. Let me quote a passage from the website of Gene Essence which illustrates this very clearly (although this company offers only health-related DNA information and thus is not of part of our major concern in this paper):

Find out what your genes can tell about yourself ... Find out how your genes can affect your health, and what makes you different from everybody else.

Take the first step towards discovering who you are (Gene Essence 2010).

Genetics is stated to be the first step towards self-discovery, but one can read between the lines that it is considered to be the most important step. It concerns what we essentially are. Other steps represent only secondary aspects. Our DNA is what fundamentally makes each of us different from everybody else. In a similar vein and 
expressing it even more explicitly, DNA Worldwide maintains (as already quoted above):

Your DNA determines who and what you are. No one has ever had the same DNA as you; it is the source of your uniqueness (DNA Worldwide 2010).

A somewhat different view can be found on the website of DNATribes. This is how this company in its FAQs section answers the question "Does DNA Tribes prove identity?":

Identity is complex and defined by a very personal combination history, geography, and culture. While a DNA test alone cannot define a person's identity, results from our analysis can provide important clues to ancestral origins within major world regions and sometimes even individual ethnic groups. Alongside genealogical, historical and cultural information, our analysis can contribute another important piece to the puzzle of personal identity (DNA Tribes 2010).

This view of the significance of genetics is more modest. DNA analysis provides only one aspect of our identity among many others. It is not stated or indicated that genetics is the most important one.

The third issue concerns essentialism versus non-essentialism. Traces of genetic essentialism can be found on, e.g., the websites (already quoted above) of Gene Essence ("Take the first step towards discovering who you are" (Gene Essence 2010)) and DNA Worldwide ("Your DNA determines who and what you are" (DNAWorldwide 2010)). Genetic essentialism is the view that our genomes define our personal identities. Our DNA defines who we are. In some ways our genomes are analogues to the "soul" in religious accounts (cf. Nordgren and Juengst 2009). However, on some websites we also find examples that point in a more nonessentialistic direction. The test results of autosomal ancestry tests may indicate higher or lower percentages of admixture or stronger or weaker matches with certain genetic regions in the world. DNA Tribes states that "in reality, no population is " $100 \%$ unmixed" or completely isolated from other populations" (DNA Tribes 2010). Our identity is not a matter of a stable core or essence.

Fourth, we have the issue of limitations of the tests. Some companies do not mention this aspect whatsoever. Some talk about providing conclusive answers, like International Biosciences:

International Biosciences can provide you with conclusive answers about your ancestry and genealogy from a very unique perspective; that of your own genetic makeup (International Biosciences 2010).

AccessDNA - which does not offer any DNA testing on its own but presents itself as "the leading online consumer resource for genetics" and which "combines high-quality content about genetics with access to, and evaluation of, relevant testing, counselling, and support services"-stresses the limitations of the tests:

Ancestry testing is not an exact science. The validity and reliability of results are sometimes disputed. In general, the larger and more diverse the collection of analyzed DNA samples, the more reliable the results (AccessDNA 2010). 


\section{Tentative explanations}

Why do some consumer genomics companies in their rhetoric appeal to identity? And more specifically, why do they appeal to individualistic and/or communitarian visions of identity? Before tentatively suggesting a few possible answers to these questions, let my briefly address two more basic issues.

First, why have these consumer genomics companies emerged at precisely this time in history? It seems obvious that this is due to two factors. The first is the emergence of the Internet in the 1990s. This technology makes it possible for companies to market their products and services directly to the consumer rather than via local providers. The second factor is the completion of the Human Genome Project in the early 2000s (International Human Genome Sequencing Consortium 2001; Venter et al. 2001). This project provided new knowledge about genetics, but also-and perhaps even more importantly - new technologies for sequencing the genome. The combination of these two factors may explain the recent emergence of the consumer genomics companies. These companies can offer DNA testing online "direct-toconsumer" and quickly provide the results by way of new rapid genetic technologies.

Second, why have the companies emerged primarily in the US? Again, the reason is probably a combination of two factors. The US has been in the frontline of genetic research for decades, and together with the fact that the US has a strong tradition of private business, the emergence of companies in the US that use and further develop the new genetic technologies of the Human Genome Project is not too surprising.

With this in mind, why do some consumer genomics companies in their rhetoric appeal to identity? My suggestion is that this rhetoric is a response to the search for identity in modern societies. Modern societies - including the US - are pluralistic, and this pluralism may make some people uncertain about who they are. In more traditional and homogeneous societies social identities are more unproblematic. They are framed by family, ethnicity and religion (cf. Taylor 1989; Kymlicka and Norman 2000; Gutmann 2003). This challenge to identity in pluralistic societies may make people interested in getting their identity affirmed by DNA testing or in finding their "true" identity (cf. Nordgren and Juengst 2009).

The more specific reason US companies offer genetic ancestry tracing might be the fact that the US is a relatively young nation built by immigrants from many different countries. People might have a special interest in investigating their biological roots. Many African-Americans seem interested in tracing their ancestry back to the specific regions in Africa from which their ancestors were taken as slaves. Moreover, some customers hope to obtain native-American tribal membership. This may give them various benefits such as financial support, housing, education and health care. Some want to challenge tribal affiliation decisions (Bolnick et al. 2007). Mixed ethnic background may also be an important reason. People want to get a clearer picture of their mixed background and therefore turn to genetic admixture testing.

Moreover, some people search for an alternative to religious accounts of personal identity and the companies may try to meet this demand. Potential customers may search for a firm ground for identity in naturalistic accounts of modern science: we are essentially our genes. This genetic identity is not something that is invented by the individual or constructed by society. It is simply given by nature and discovered by science (cf. Nordgren and Juengst 2009). 
Furthermore, some people may be interested in social networking, and now we have a new medium for this, the Internet. Facebook and MySpace are examples of popular tools for such social networking. In a similar vein, by using the online DNA testing services of the consumer genomics companies people may find others of the same kind, i.e., others that belong to the same genetic community (in the various senses presented above).

Now, why are there individualistic visions of identity on the websites and why are there communitarian visions? It seems obvious that the two visions represent two different types of rhetoric that may appeal to different types of customers. Some customers are individualists and look for support of their unique identity in DNA testing. For other people belonging to a community is highly valued. DNA testing may provide the information that they belong to a specific genetic community. This gives them a community-based identity. A third category is interested in both individualistic and communitarian accounts. Let me stress that these suggestions are merely hypotheses that need to be investigated further by sociologists and psychologists.

Finally, a comment on the option that customers may seek both health-related and non-health-related DNA information. Some people may start ordering health-related DNA tests, others non-heath-related ones. After trying one type of test, they may get interested in the other type. Certainly, both types of tests may provide input to identity, however in this paper I have focused exclusively on non-health-related tests. Explaining the interest in health-related DNA testing may require other explanations (see, however, Nordgren and Juengst 2009).

\section{Conclusions}

In this paper, I have analysed the rhetoric appeal to identity that can be found on websites of companies offering non-health-related DNA testing. I have established that some websites in their rhetoric display individualistic and/or communitarian visions of identity.

According to the individualistic visions, the DNA of an individual gives the individual a unique identity, which also remains the same over time. In support for these visions, websites refer to the method of DNA fingerprinting.

DNA fingerprinting is also used in, for example, paternity testing and sibling testing, and such testing is referred to as support for communitarian visions of family identity. Other communitarian visions of identity are supported by reference to genetic ancestry tracing. The precise character of these visions varies depending on which particular DNA testing method is used. I have distinguished mtDNA haplogroup identity, Y chromosome haplogroup identity, biogeographic identity, and pedigree identity. Biogeographic identity raises questions about racial and ethnical divisions. Some companies argue that such divisions are useful. Another view is that they are non-scientific. Companies also have different views on genetic individualism versus genetic communitarianism, on whether identity is a biological discovery or a social construction, on essentialism versus non-essentialism, and on the limitations of the DNA tests.

Finally, I have given a few tentative suggestions regarding possible explanations to the rhetoric appeal to identity by the consumer genomics companies. More 
generally, the pluralism in modern societies may make some people uncertain about who they are and make them search for a firm ground for identity in naturalistic accounts of modern science (genetics). The rhetoric on the websites can be seen as a response to this search for identity. More specifically, different customers may be attracted to different types of rhetoric regarding identity. Some customers are individualists and may be attracted to individualistic visions of identity. For others belonging to a community is important and they are attracted to communitarian visions. A third category is attracted to both types of vision.

In the paper, I have not investigated whether the DNA tests used by the companies are scientifically adequate. Neither have I discussed whether the companies are justified in referring to these tests as support for their visions of identity. The issue of scientific adequacy of tests is an empirical issue to be assessed by geneticists. The issue of justification of references to DNA tests as support for various visions of identity requires further philosophical analysis. Both issues are important to investigate for ethical reasons. If the DNA tests offered by the companies are not scientifically adequate, customers run the risk of being misinformed and get a distorted understanding of their identities. If the references to the tests as support for various visions of identity are not justified, consumers might be misled and misinterpret their identities. However, it is beyond the purpose of this paper to discuss these further issues.

Open Access This article is distributed under the terms of the Creative Commons Attribution Noncommercial License which permits any noncommercial use, distribution, and reproduction in any medium, provided the original author(s) and source are credited.

\section{References}

AccessDNA. Homepage. http://www.accessdna.com (2010). Accessed 9 February 2010.

African Ancestry. Homepage. http://www.africanancestry.com (2010). Accessed 9 February 2010.

Ancestor.com. Homepage. http://www.ancestor.com (2010). Accessed 9 February 2010.

Ancestor-DNA. Homepage. http://www.ancestor-dna.com (2010). Accessed 9 February 2010.

Ancestry.com. Homepage. http://www.ancestry.com (2010). Accessed 9 February 2010.

Bolnick DA, Fullwiley D, Duster T, Cooper RS, Fujimura JH, Kahn J, et al. Genetics. The science and business of genetic ancestry testing. Science. 2007;318:399-400.

Borry P. Direct-to-consumer testing in the age of personalized medicine. Personalized Medicine. 2009;6:617-9. deCODEme. Homepage. http://www.decodeme.com (2010). Accessed 9 February 2010.

Determigene. Homepage. http://www.determigene.com (2010). Accessed 9 February 2010.

DNA Ancestry Project. Homepage. http://www.dnaancestryproject.com (2010). Accessed 9 February 2010.

DNA Consultants. Homepage. http://www.dnaconsultants.com (2010). Accessed 9 February 2010.

DNA Diagnostics Center. Homepage. http://www.dnacenter.com (2010). Accessed 9 February 2010.

DNA Direct. Homepage. http://www.dnadirect.com (2010). Accessed 9 February 2010.

DNA Heritage. Homepage. http://www.dnaheritage.com (2010). Accessed 9 February 2010.

DNAPrint Genomics. Homepage. http://www.dnaprint.com (2010). Accessed 9 February 2010.

DNA Tribes. Homepage. http://www.dnatribes.com (2010). Accessed 9 February 2010.

DNA Worldwide. Homepage. http://www.dna-worldwide.com (2010). Accessed 9 February 2010.

EthnoAncestry. Homepage. http://www.ethnoancestry.com (2010). Accessed 9 February 2010.

Family Helix. Homepage. http://www.familyhelix.com (2010). Accessed 9 February 2010.

Family Tree DNA. Homepage. http://www.familytreedna.com (2010). Accessed 9 February 2010.

Gene Essence. Homepage. http://www.geneessence.com (2010). Accessed 9 February 2010.

Genelex. Homepage. http://www.healthanddna.com (2010). Accessed 9 February 2010.

Genetree. Homepage. http://www.genetree.com (2010). Accessed 9 February 2010. 
GTLDNA. Homepage. http://www.gtldna.com (2010). Accessed 9 February 2010.

Gutmann A. Identity in democracy. Princeton: Princeton University Press; 2003.

Hogarth S, Javitt G, Melzer D. The current landscape for direct-to-consumer genetic testing: legal, ethical, and policy issues. Annu Rev Genom Hum Genet. 2008;9:161-82.

Homednadirect. Homepage. http://www.homednadirect.com (2010). Accessed 9 February 2010.

Hudson K, Javitt G, Burke W, Byers P, with the ASHG (American Society of Human Genetics) Social Issues Committee. ASHG statement on direct-to-consumer genetic testing in the United States. Am J Hum Genet. 2007;81:635-7.

Human Genetics Commission. Genes Direct: Ensuring the effective oversight of genetic tests supplied directly to the public. http://www.hgc.gov.uk (2003). Accessed 1 June 2010.

Human Genetics Commission. More Genes Direct: A report on the availability, marketing and regulation of genetics tests supplied directly to the public. http://www.hgc.gov.uk (2007). Accessed 1 June 2010.

Identigene. Homepage. http://www.dnatesting.com (2010). Accessed 9 February 2010.

International Biosciences. Homepage. http://www.ibdna.com (2010). Accessed 9 February 2010.

International Human Genome Sequencing Consortium. Initial sequencing and analysis of the human genome. Nature. 2001;409:860-921.

Kaye J. The regulation of direct-to-consumer genetic tests. Hum Mol Genet. 2008;17(R2):R180-3.

Knome. Homepage. http://www.knome.com (2010). Accessed 9 February 2010.

Kymlicka W, Norman W, editors. Citizenship in diverse societies. Oxford: Oxford University Press; 2000.

MacIntyre A. After virtue. London: Duckworth; 1981.

Mygene. Homepage. http://www.mygene.net.au (2010). Accessed 9 February 2010.

Mygenetree. Homepage. http://www.mygenetree.com (2010). Accessed 9 February 2010.

Navigenics. Homepage. http://www.navigenics.com (2010). Accessed 9 February 2010.

Nimble Diagnostics. Homepage. http://www.nimblediagnostics.com (2010). Accessed 9 February 2010.

Nordgren A. Genetics and identity. Community Genet. 2008;11:252-66.

Nordgren A, Juengst ET. Can genomics tell me who I am? Essentialistic rhetoric in direct-to-consumer DNA testing. New Genet Soc. 2009;28:157-72.

Oxford Ancestors. Homepage. http://www.oxfordancestors.com (2010). Accessed 9 February 2010.

Parfit D. Reasons and persons. Oxford: Clarendon; 1984.

Roots For Real. Homepage. http://www.rootsforreal.com (2010). Accessed 9 February 2010.

Sykes B. The seven daughters of Eve: the science that reveals our genetic ancestry. London: Bantam; 2001.

Taylor C. Sources of self: the making of the modern identity. Cambridge: Cambridge University Press; 1989.

The Genographic project. Homepage. https://genographic.nationalgeographic.com (2010). Accessed 9 February 2010.

Venter JC et al. The human genome: the sequence of the human genome. Science. 2001;291:1304-51.

Warrior Roots. Homepage. http://www.warriorroots.com (2010). Accessed 9 February 2010.

23 andMe. Homepage. https://www.23andme.com (2010). Accessed 9 February 2010. 